\title{
Cloning, expression, and biochemical characterization of a cold- active GDSL-esterase of a Pseudomonas sp. S9 isolated from Spitsbergen island soil
}

\author{
Monika Wicka, Marta Wanarska, Ewelina Krajewska, Anna Pawlak-Szukalska, Józef Kur and \\ Hubert Cieśliński ${ }^{\bowtie}$
}

Department of Molecular Biotechnology and Microbiology, Gdańsk University of Technology, Gdańsk, Poland

\begin{abstract}
An estS9 gene, encoding an esterase of the psychrotolerant bacterium Pseudomonas sp. S9 was cloned and sequenced. The deduced sequence revealed a protein of 636 amino acid residues with a molecular mass of $69 \mathrm{kDa}$. Further amino acid sequence analysis revealed that the EstS9 enzyme contained a G-D-S-L motif centered at a catalytic serine, an N-terminal catalytic domain and a C-terminal autotransporter domain. Two recombinant $E$. coli strains for production of EstS9N (a two domain enzyme) and EstS9 $\Delta$ (a one domain enzyme) proteins were constructed, respectively. Both recombinant proteins were successfully produced as inclusion bodies and then purified under denaturing conditions. However, because of the low enzymatic activity of the refolded EstS9 $\Delta$ protein, only the EstS9N protein was further characterized. The purified and refolded EstS9N protein was active towards short-chain $p$-nitrophenyl esters (C2-C8), with optimal activity for the butyrate (C4) ester. With $p$-nitrophenyl butyrate as the substrate, the enzyme displayed optimal activity at $35^{\circ} \mathrm{C}$ and $\mathrm{pH}$ 9.0. Additionally, the EstS9N esterase retained $\sim 90 \%$ of its activity from $25-40^{\circ} \mathrm{C}$ and $\sim 40 \%$ of its activity at $10^{\circ} \mathrm{C}$. Moreover, analysis of its kinetic parameters $\left(K_{\mathrm{m}}, k_{\mathrm{cat}}, k_{\mathrm{cat}} / K_{\mathrm{m}}\right)$ toward $p$-nitrophenyl butyrate determined at $15^{\circ} \mathrm{C}$ and $25^{\circ} \mathrm{C}$ confirmed that the EstS9 enzyme is cold-adapted. To the best of our knowledge, EstS9 is the third characterized cold-active GDSL-esterase and the first one confirmed to contain an autotransporter domain characteristic for enzymes secreted by the type V secretion system.
\end{abstract}

Key words: GDSL-family, cold-active, esterase, autotransporter, Pseudomonas sp. S9

Received: 01 June, 2015; revised: 28 June, 2015; accepted: 22 November, 2015; available on-line: 28 January, 2016

\section{INTRODUCTION}

Lipolytic enzymes comprising carboxylesterases (EC 3.1.1.1), phospholipases (EC 3.1.1.2) and lipases (EC 3.1.1.3) are $\alpha / \beta$ hydrolases that catalyze the hydrolysis and synthesis of acylglycerides and other fatty acid esters. Many of them do not require cofactors and have regio- and stereo-selectivity (Arpigny \& Jaeger, 1999). They have also broad substrate specificity, and can exhibit organic solvent-stable catalytic activities. Hence, among this group of enzymes, carboxylesterases (EC 3.1.1.1) and lipases (EC 3.1.1.3) are important industrial enzymes with numerous applications in biotechnology (Fojan et al., 2000).
Cold-active enzymes have received increasing attention because of their relevance to the development of new industrial applications in various fields of biotechnology. This group of enzymes, in contrast to mesophilic and thermophilic enzymes, is characterized by high catalytic efficiency at low temperatures $\left(0-10^{\circ} \mathrm{C}\right)$ and usually rapid inactivation at temperatures above the enzymatic activity optimum (30 to $40^{\circ} \mathrm{C}$ ). Therefore, use of cold-active enzymes in industrial processes can prevent the loss of thermosensitive substrates and products. However, the main advantage of use of these enzymes in industry can be the reduction of heat consumption in bioreactors. Furthermore, if necessary, after use, most of cold-active enzymes can be easily inactivated by a relatively slight elevation in temperature. Moreover, in the food industry, the use of cold active enzymes for low-temperature processes can reduce the risk of contamination by mesophilic microorganisms and eliminate undesired changes in the taste and nutritional values of the foodstuffs (Cavicchioli et al., 2011).

Thus, cold-active lipases and esterases may be used as additives in food processes (e.g. cheese manufacturing, baking) (Esteban-Torres et al., 2014), additives in laundry detergents (cold washing), and as biocatalysts for the organic syntheses of thermolabile compounds at low temperatures (Kulakova et al., 2004). Moreover, cold-active lipolytic enzymes can be also used for bioremediation of polluted soils and wastewaters, at low and moderate temperatures (Novototskaya-Vlasova et al., 2012).

This study focuses on the characterization of a coldactive EstS9 esterase from the psychrotolerant bacterium Pseudomonas sp. strain S9. In contrast to most well characterized cold-active esterases containing a conserved G$\mathrm{X}-\mathrm{S}-\mathrm{X}-\mathrm{G}$ consensus sequence centered around the catalytic serine (Suzuki et al., 2002; Kulakova et al., 2004; Soror et al., 2007; Heath et al., 2009; Fu et al., 2011; Kang et al., 2011; Brault et al., 2012; Hu et al., 2012; Jiang et al., 2012; Jimenez et al., 2012; Novototskaya-Vlasova et al., 2012; Lemak et al., 2012; Abdul Salam et al., 2013; Berlemont et al., 2013; Fu et al., 2013; Kim et al., 2014) the EstS9 harbors another conserved sequence G-DS-L around this catalytic residue. To the best of our knowledge, the EstS9 is the third cold-active esterase belonging to the GDSL subfamily of lipolytic enzymes

\footnotetext{
e-mail: hcieslin@pg.gda.pl
}

Abbreviations: $K_{\mathrm{m}}$, Michaelis constant; $k_{\mathrm{cat}}$ turnover number; $k_{\mathrm{cat}}$ / $K_{\mathrm{m}}$ specificity constant; SDS-PAGE, sodium dodecyl sulfate polyacrylamide gel electrophoresis; DDT, dithiothreitol; EDTA, ethylenediaminetetraacetic acid; ORF, open reading frame 
(Suzuki et al., 2003; Cieslinski et al., 2007) described to date. Moreover, analysis of the amino acid sequence of EstS9 also revealed that this enzyme is comprised of two domains: an N-terminal catalytic domain and a Cterminal autotransporter domain. Interestingly, a review of the literature did not reveal any reports on the identification and characterization of cold-active esterases with C-terminal autotransporter domains. However, we determined that a previously identified and characterized cold-active esterase, PsEst1 esterase from Pseudomonas sp. strain B11-1, is also comprised of an N-terminal catalytic domain (GDSL subfamily) and a C-terminal autotransporter domain. The presence of a C-terminal autotransporter domain in PsEst1 was not reported in published data (Suzuki et al., 2003). Hence, the present study is the first report of the identification and characterization of a cold-active GDSL esterase containing a C-terminal autotransporter domain.

\section{MATERIALS AND METHODS}

Characterization and identification of the S9 strain. The growth properties of the S9 strain were determined in Difco Marine broth 2216 (Becton, Dickinson and Company, abr. DM medium). The proteolytic, lipolytic and amylolytic activities of the strain were examined at $20^{\circ} \mathrm{C}$ on agar solidified DM medium supplemented with skimmed milk, tributyrin, or starch, respectively.

The genus of the S9 strain was assessed on the basis of its $16 \mathrm{~S}$ rDNA gene sequence, amplified by PCR with primers fD1 and rP2 (Weisburg et al., 1991). Then, the $16 \mathrm{~S}$ rDNA PCR product was sequenced and the resulting DNA sequence was compared with those from the Ribosomal Database Project and the NCBI database aligned using the MEGA 5.0 http://www.megasoftware. net/ website.

Genomic DNA library construction and esterase gene identification. The genomic DNA from Pseudomonas sp. S9 cells was isolated and purified using a Genomic Mini AX Bacteria (A\&A Biotechnology, Poland) according to the protocol with one exception. The protocol step 'incubation with the lysozyme' was extended to 1 hour. Then, the genomic DNA was digested using the EcoRI endonuclease (Thermo Scientific, USA), and the resulting DNA fragments were purified by an ethanol precipitation and cloned into a pZErO-2 vector (Invitrogen, USA) which was linearized by digestion with endonuclease EcoRI and purified by Extractme DNA Clean-Up kit (Blirt S.A., Poland). The ligated DNA was transformed into E. coli TOP10 cells and the resulting DNA library was screened for lipolytically active clones on double layered Luria-Bertani agar plates, called LBT2. The bottom layer was supplemented with $25 \mu \mathrm{g} \mathrm{mL}-1$ kanamycin, while the top layer contained $25 \mu \mathrm{g} \mathrm{mL}-1$ kanamycin, $1 \%$ (v/v) tributyrin, and $0.3 \mathrm{mM} \mathrm{IPTG.} \mathrm{The}$ kanamycin, tributyrin, and IPTG were purchased from Sigma (USA). The plates were incubated at $37^{\circ} \mathrm{C}$ for $24 \mathrm{~h}$ and then transferred to $25^{\circ} \mathrm{C}$ for $8 \mathrm{~h}$ incubation. Afterwards, the plates were screened for the presence of recombinant colonies with lipolytic activity, which was identified by their ability to form a clear halo around the colonies.

Bioinformatics analyses. Bioinformatics analyses of the DNA insert of $\mathrm{pZErO}-2 / \mathrm{Lip} 1$ vector, and amino acid sequences of PsEts1, EstS9, EstS9N and EstS9 $\Delta$ proteins were done with a set of bioinformatics tools used in our previous study (Wierzbicka-Wos et al., 2013), with one exception. The PSORT program was not used in this study. Topographic presentations of the Pfam domains for PsEts1, EstS9, EstS9N, and EstS9D (Fig. 1) were done with a MyDomains - Image Creator (http:// prosite.expasy.org/mydomains/).

Construction of an $E$. coli TOP10/pBADestS9N strain. A PCR product, called estS9N, was amplified using the following primers: FLipS9Nco CAGTCCATGGCGCCTAATCCT'TACACCCAT'T'TCGTCG and RLipS9Hind-His CTAGAAGCTTGAAGTCCAGCGCAACGCCTACATTAAATAC. The NcoI and HindIII restriction sites were incorporated into the forward and reverse primer sequences, respectively. The recognition sites for the restriction endonucleases are underlined and were designed to facilitate cloning. Unfortunately, because of the presence of a NcoI restriction site inside the DNA sequence coding the EstS9 esterase, a plasmid pBADestS9N was constructed in two steps as shown in Fig. 2. Finally, the recombinant pBADestS9N plasmid was transformed into E. coli TOP10, and the resulting recombinant E. coli strain produced EstS9N (pBAD expression system; Invitrogen, USA), which was composed of an N-terminal catalytic domain, AB-transporter domain, and a C-terminal His-tag domain (Fig. 1C).

Construction of an E. coli TOP10/pBADestS9 $\Delta$ strain. A PCR product, called estS9 $\Delta$, was amplified using the following primers: FLipS9Nco CAGTCCATGGCGCCTAATCCT'TACACCCATT'TCGTCG and RLipS9shortHind-His GATC AAGCTTGCGTTGCCCTGCTTCGGTCGG. The NcoI and HindIII restriction sites were incorporated into the forward and reverse primer sequences, respectively. The recognition sites for the restriction endonucleases are underlined and were designed to facilitate cloning.

The estS9 $\triangle$ PCR product was purified using an Extractme DNA Clean-Up kit (Blirt S.A., Poland), then digested with NcoI and HindIII endonucleases and purified by ethanol precipitation. The purified DNA insert was ligated to the $\mathrm{pBAD} / M y c$-His $\mathrm{A}$ expression vector (pBAD expression system; Invitrogen, USA), previously linearized with the same endonucleases. Finally, the recombinant $\mathrm{pBAD}$ estS9 $\Delta$ plasmid was transformed into E. coli TOP10, to yield the resulting recombinant EstS9 $\Delta$

(A)

(B)
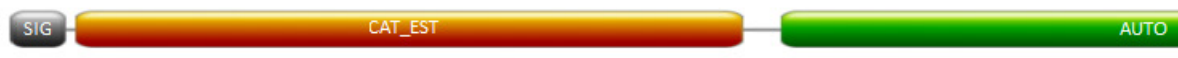

SIG

(C)

(D)

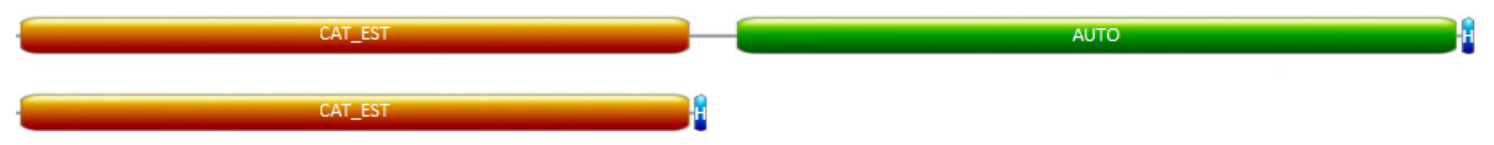

Figure 1. Topographic presentation of the Pfam domains for PsEts1 (A), EstS9 (B), EstS9N (C), and EstS9D (D).

SIG (grey domain), putative signal sequence; CAT_EST (orange domain), catalytic domain; AUTO (green domain), autotransporter domain; $\mathrm{H}$ (blue domain), His-Tag. 
protein which was composed of an N-terminal catalytic domain and a C-terminal His-tag domain (Fig. 1D).

Expression and purification of the recombinant enzymes. The E. coli TOP10/pBADestS9N and E. coli TOP10/pBADestS9 $\Delta$ were grown in Luria-Bertani medium (1 L) containing ampicillin $\left(0.1 \mathrm{mg} \mathrm{mL}^{-1}\right)$, and incubated with agitation at $37^{\circ} \mathrm{C}$ to an $\mathrm{OD}_{600}$ of 0.5 . The cultures were then supplemented with L-arabinose $(0.2 \%$ $\mathrm{w} / \mathrm{v})$ to induce the expression of the estS9N and est59D genes and grown for $20 \mathrm{~h}$ at $30^{\circ} \mathrm{C}$. Next, the E. coli cells were harvested by centrifugation at $4^{\circ} \mathrm{C}$ and $4600 \times g$ for $15 \mathrm{~min}$. Cell pellet was suspended in $50 \mathrm{~mL}$ of buffer B5 (20 mM Tris-HCl, 0.5 M NaCl, $6 \mathrm{M}$ urea, $5 \mathrm{mM}$ imidazole, $\mathrm{pH}$ 7.9), and then the E. coli cells were disrupted by sonication. Cell debris was collected by centrifugation at $12800 \times \mathrm{g}$ for $20 \mathrm{~min}$ at $4^{\circ} \mathrm{C}$, and then $50 \mathrm{~mL}$ of the cell-free extract was applied onto an Ni-NTA column pre-equilibrated with buffer B5. Then, the Ni-NTA column was washed out with an imidazole gradient from 5-60 mM in buffer B5. Finally, the elution step was carried out with buffer EU (20 mM Tris- $\mathrm{HCl}, 0.5 \mathrm{M} \mathrm{NaCl}$, $6 \mathrm{M}$ urea, $500 \mathrm{mM}$ imidazole, $\mathrm{pH}$ 7.9) at a flow rate of

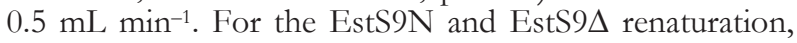
the proteins in buffer EU were dialyzed against buffer $\mathrm{R}$ (20 mM Tris- $\mathrm{HCl}$ buffer, $\mathrm{pH} 7.5$, containing $0.1 \%$ Triton $\mathrm{X}-100)$, where the concentration of urea decreased $(6.0$ to $\sim 0.0 \mathrm{M})$ during dialysis (for $120 \mathrm{~h}$ ).

The molecular weights of the denatured EstS9N and EstS9 $\Delta$ proteins were estimated using SDS-PAGE (Laemmli, 1970). The protein concentration in the eluted fractions was determined by measuring the absorbance at $280 \mathrm{~nm}$ (BioSpectrometer Kinetic, Eppendorf, Germany).

Substrate specificity. The substrate specificity of the purified enzyme was determined at $25^{\circ} \mathrm{C}$ using $50 \mathrm{mM}$ solutions of $p$-nitrophenyl acetate, $p$-nitrophenyl butyrate, $p$-nitrophenyl caprylate, and $p$-nitrophenyl decanoate in acetonitrile and $p$-nitrophenyl palmitate, and $p$-nitrophenyl stearate in $n$-hexane. Assays were performed by measuring the increase in absorbance at $405 \mathrm{~nm}$ as a result of the release of $p$-nitrophenol upon the hydrolysis of the substrates.

One unit of enzyme activity (U) was defined as the enzyme activity required for release of $1 \mu \mathrm{mol}$ of $p$-nitrophenol from $p$-nitrophenol butyrate per minute under the above presented conditions.

Effect of temperature and $\mathrm{pH}$ on esterase activity. The effect of temperature on the esterase was assayed by incubating the reaction mixtures at temperatures ranging from 5 to $60^{\circ} \mathrm{C}$ (in $5^{\circ} \mathrm{C}$ increments) and measuring the activity at the same temperature with p-nitrophenyl butyrate at a final concentration of $3.6 \mathrm{mM}$, in $20 \mathrm{mM}$ Tris- $\mathrm{HCl}$ buffer, $\mathrm{pH}$ 7.5. The enzymatic reactions were stopped after $9 \mathrm{~min}$ with isopropanol.

The optimum $\mathrm{pH}$ was determined by assaying the activity of the EstS9-His enzyme in a $10 \mathrm{mM}$ Britton-Robinson buffer, with $\mathrm{pH}$ values ranging from 2.0 to 12.0 . The enzymatic activities were quantitated at the tested $\mathrm{pH}$ value at $25^{\circ} \mathrm{C}$ with $p$-nitrophenyl butyrate. The enzymatic reactions were stopped after $9 \mathrm{~min}$ with isopropanol.

For the thermal stability assays, the purified enzyme was pre-incubated at $40,50,60,70,80$ and $90^{\circ} \mathrm{C}$ in the absence of $p$-nitrophenyl butyrate. After incubating for different times $(20,40,80,180$ and $300 \mathrm{~min})$, the activity was measured by assaying the residual activities at $\mathrm{pH}$ $9.0,25^{\circ} \mathrm{C}$. The enzymatic reactions were stopped after 9 min with isopropanol.
For the $\mathrm{pH}$ stability assays, the reaction mixtures containing the appropriate substrates were incubated at $25^{\circ} \mathrm{C}$ and $\mathrm{pH}$ ranging from 5.0 to 11.0 . After incubating for 20, 40 and $60 \mathrm{~min}$, sample mixtures were withdrawn, and the residual enzymatic activities were measured with p-nitrophenyl butyrate in $20 \mathrm{mM}$ Tris- $\mathrm{HCl}$ buffer $\mathrm{pH} 9.0$ at $25^{\circ} \mathrm{C}$. The enzymatic reactions were stopped after 9 min with isopropanol.

All the experiments were performed in triplicate.

Effects of selected metal ions and reagents on the enzymatic activity of EstS9N. The effects of DT'T, oxidized glutathione, reduced glutathione, 2-mercaptoethanol, EDTA, and selected metal ions $\left(\mathrm{Mg}^{2+}, \mathrm{Ca}^{2+}, \mathrm{Mn}^{2+}\right.$, $\mathrm{Ni}^{2+}, \mathrm{Co}^{2+}$ ) at final concentrations of $5 \mathrm{mM}$, on EstS9N esterase activity were assayed in $20 \mathrm{mM}$ Tris- $\mathrm{HCl}$ buffer, at $25^{\circ} \mathrm{C}$ and $\mathrm{pH} 9.0$, with $3.6 \mathrm{mM}$-nitrophenyl butyrate as substrate.

Sequence Accession Numbers. The estS9 and 16S rDNA gene sequences reported in this work have been deposited in the GenBank database and assigned the accession numbers KP645181 and KP645182, respectively.

\section{RESULTS AND DISCUSSION}

\section{Characterization and identification of the bacterial strain S9}

Bacterial strain S9 was isolated from a soil sample collected in the vicinity of the Polish polar station at Isbjørnhamna in Hornsund fjord on the Spitsbergen island $\left(77^{\circ} 0^{\prime} 0^{\prime \prime} \mathrm{N}, 15^{\circ} 33^{\prime} 0{ }^{\prime} \mathrm{E}\right)$. The cells of the S9 strain were Gram-negative, aerobic, non-motile and rod-shaped. On Marine broth agar, this strain formed small, round, smooth, beige colonies with a diameter of 1.5-2 $\mathrm{mm}$. The optimal growth temperature for colonies was $20^{\circ} \mathrm{C}$ and growth was poor below $10^{\circ} \mathrm{C}$ and above $30^{\circ} \mathrm{C}$. The strain displayed a high lipolytic activity on tributyrin agar, and a poor proteolytic activity on milk agar (growth at $20^{\circ} \mathrm{C}$ ), respectively.

An alignment of the 16S rDNA gene sequence of the S9 strain with the appropriate sequences available in the Ribosomal Database Project and the GenBank database, demonstrated that the S9 strain should be classified as a Psendomonas sp., and that its closest relatives were Pseudomonas mandelii, strain Asd MV-11 (GenBank:FM955880), Pseudomonas sp. PR3-10 (GenBank: FJ889634), Pseudomonas sp. SE22\#2 (GenBank: AY263478) with 99\% sequence identity (identities 1460/1461; gaps: 0/1461) and $100 \%$ query coverage, respectively. Interestingly, Pseudomonas mandelii, strain Asd MV-11, and Pseudomonas sp. PR3-10 were also isolated from environmental samples collected in Spitsbergen, however, Pseudomonas sp. SE22\#2 was isolated from alpine soil. Psendomonas mandelii, strain AsdMV-11, also displayed a lipolytic activity (Reddy et al., 2009). However, to the best of our knowledge, identification of an enzyme(s) associated with the lipolytic activity of strain AsdMV-11 has not been isolated or characterized to date. Moreover, in contrast to strain AsdMV-11, Pseudomonas sp. S9 did not display an amylase activity.

\section{Construction of a Pseudomonas sp. S9 genomic library and screening for clones encoding lipolytic activity}

To isolate the gene encoding an enzyme with lipolytic activity, a genomic DNA library was constructed using DNA isolated from Pseudomonas sp. S9 and pZErO-2 vector. Next, the resulting DNA library 


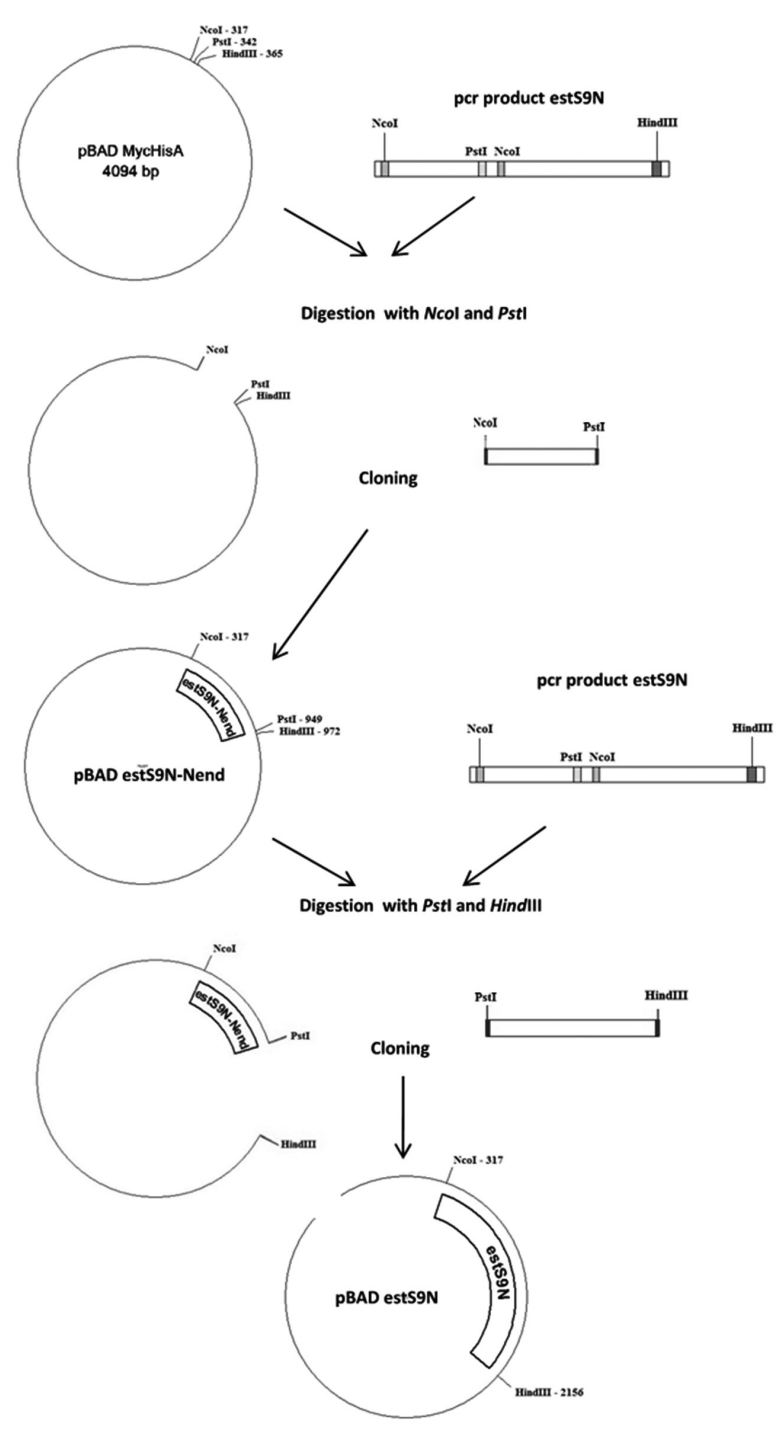

Figure 2. Construction of the pBADestS9N plasmid.

was screened for recombinant E. coli colonies displaying lipolytic activity towards tributyrin on LBT2 agar plates. The screening revealed one colony (named S9_Lib1) among approximately 3000, which exhibited such lipolytic activity. The restriction analysis of pZErO-S9 Lib1, a recombinant plasmid isolated from the S9_Lib1, showed that this clone contained a Pseudomonas sp. S9 genomic DNA fragment of about $10 \mathrm{~kb}$. Next, a series of plasmids with different fragments of the DNA insert of the pZErO-S9 Lib1 plasmid was constructed and used for transformation of E. coli TOP10. Finally, we found that the resulting lipolytic clones harbored the same recombinant plasmid, designated as pZErO-S9 Lib1/NotI, containing a Pseudomonas sp. S9 genomic DNA fragment of about $3.0 \mathrm{~kb}$.

\section{Sequence analysis of the genomic DNA insert of pZErO-S9 Lib1}

Bioinformatics analysis of DNA and protein sequences have been carried out in accordance with the methodology presented in our previous article (Wierzbicka-Wos et al., 2013).
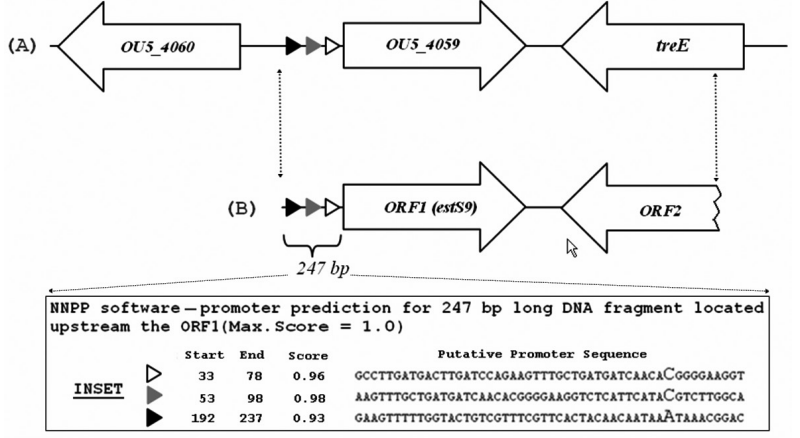

Figure 3. The presence of open reading frames (ORFs) in the genomic insert of Pseudomonas sp. S9 (A) and how they correspond with the arrangement of the homologous genes on Pseudomonas mandelii JR-1 (B).

INSET - result of in silica prediction of sequences of putative promoters for 247 bp long DNA fragment located upstream the OU5_4059 (A) and the ORF1 (B), respectively

The nucleotide sequence analysis revealed that the DNA insert of the pZErO-S9 Lib1/NotI plasmid contained a complete ORF1 at the 5' terminal, and a partial ORF2 at the 3' terminal (Fig. 3). The complete ORF1 and the partial ORF2 had the highest sequence homology to the DNA sequences of the OU5_4059 and treE genes from the cold-adapted Pseudomonas mandelii JR-1, respectively (Jang et al., 2012). In the light of the data deposited in the Genbank database, the OU5_4059 and treE genes encoded a putative outer membrane autotransporter barrel (GenBank: AHZ71138.1) and a putative anthranilate synthase component I (GenBank: AHZ71137.1), respectively. However, more importantly for this study, the product of translation in silico of the ORF1 showed high sequence similarity with many putative lipolytic enzymes belonging to $\alpha / \beta$ hydrolases whose sequences are deposited in the Protein database at National Center for Biotechnology Information (USA).

On the other hand, the layout of the ORFs from the Pseudomonas sp. S9 genomic DNA insert (Fig. 3) corresponds to the layout of the OU5_4059 and treE genes in the genome of Pseudomonas mandelii JR-1 (NCBI reference sequence: NZ_AJFM00000000.1). Interestingly, orientation of the neighboring genes to the OU5_4059 gene on the genome of Ps. mandelii JR-1 suggests that this gene is expressed from its own promoter. Unfortunately, the analysis of a $\sim 3 \mathrm{~kb}$ long genomic DNA insert of Pseudomonas sp. S9 from the pZErO-S9 Lib1/ NotI plasmid did not confirm the presence of any other ORFs upstream of ORF1. However, the alignment of a $247 \mathrm{bp}$ long DNA fragment located upstream of the ORF1 revealed DNA identities of $97 \%$ with a $247 \mathrm{bp}$ long DNA fragment located upstream of the OU5_4059 gene. This observation led us to analyze both highly conserved DNA fragments using two on-line tools dedicated for prediction of putative promoter sequences. The analysis of both DNA fragments using the NNPP software revealed three highly conserved putative promoter sequences located at the same place in the analyzed DNA fragments (see Inset, Fig. 3). Interestingly, the alternative analysis of both DNA fragments using BProm program revealed only the presence of one putative promoter but with an identical DNA sequence and location as the third putative promoter predicted with NNPP software (black triangle at Inset; Fig. 3). For this reason, it appears 
highly possible that the gene encoding the lipolytic enzyme corresponding to ORF1 was expressed from its own promoter in the cells of the E. coli/S9_Lib1 clone and E. coli/S9_Lib1_NotI clone, respectively.

As mentioned above, the result of the tblastx search revealed that the protein encoded by ORF1 shared the highest sequence identity $(97 \%)$ with protein annotated not as a putative lipolytic enzyme, but as a putative outer membrane autotransporter barrel in Pseudomonas mandelii JR-1 (Jang et al., 2012). However, further detailed analysis of this result revealed that this protein also shared a high sequence identity (91\%) with a cold-adapted and biochemically characterized PsEst1 esterase from Pseudomonas sp. strain B11-1 (GenBank No.: BAC21259) (Suzuki et al., 2003). Hence, we hypothesized that the ORF1, named estS9 gene, encoded a putative cold-active and esterolytic enzyme of Pseudomonas sp. S9.

The deduced product of the estS9 gene consisted of 636 amino acid residues with a calculated molecular mass of 68,739 Da. Analysis of the amino acid sequence of EstS9 with InterProScan 5 and CD-search revealed that this protein is composed of two putative domains: a SGNH hydrolase-type esterase/lipase domain ( 29-320) and an autotransporter beta domain ( 360-626). Moreover, the analysis also revealed the presence of a putative signal peptide of EstS9 enzyme (1-19) which may be involved in EstA transport to the periplasmic space of the host cell (Fig. 1). The detailed sequence analysis of the SGNH hydrolase-type domain of EstS9 revealed that the enzyme contains a canonical putative catalytic triad that would be formed by residues: $\mathrm{Ser}^{38}$, Asp ${ }^{162}$ and $\mathrm{His}^{303}$. Importantly, in contrast to more well-characterized cold-active esterases which contain a catalytic serine residue arranged within the consensus sequence G-X-S-X-G (Suzuki et al., 2002; Kulakova et al., 2004; Soror et al., 2007; Heath et al., 2009; Fu et al., 2011; Kang et al., 2011; Brault et al., 2012; Jiang et al., 2012; Jimenez et al., 2012; Lemak et al., 2012; Novototskaya-Vlasova et al., 2012; Abdul Salam et al., 2013; Berlemont et al., 2013; Fu et al., 2013; Kim et al., 2014), the catalytic serine residue of EstS9 $\left(\mathrm{Ser}^{38}\right)$ is part of another conserved sequence motif, G-D-S-L. More importantly, this sequence motif is characteristic of the GDSL subfamily of lipolytic enzymes. An important differentiating feature of the GDSL subfamily of lipolytic enzymes is that the sequence motif containing the catalytic serine residue is closer to the $\mathrm{N}$-terminus, unlike oth-

A

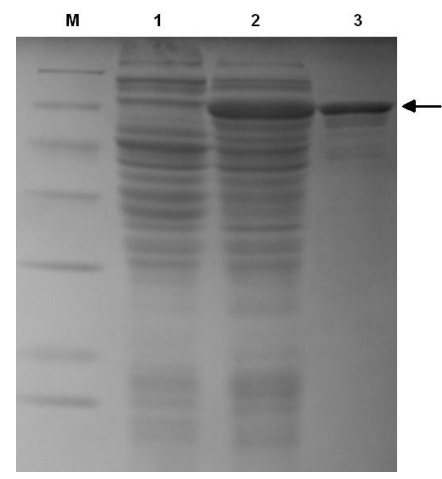

Figure 4A. SDS-PAGE protein profiles: (M) Unstained Protein Molecular Weight Marker 116, 66.2, 45, 35, 25, 18.4, 14.4 kDa (Thermo Scientific, USA), (1) Cell-free extract of $E$. coli TOP10/ pBADestS9N, (2) Cell extract of E. coli TOP10/pBADestS9N after solubilization of inclusion bodies (3) Purified EstS9N after renaturation er lipases and esterases, where the GXSXG motif is close to the center of the enzyme's sequence (Akoh et al., 2004). To date, to the best of our knowledge, only two other cold-active esterases belonging to the GDSL subfamily, i.e. EstA esterase $(\sim 23 \mathrm{kDa})$ from Pseudoalteromonas sp. 643A (Cieslinski et al., 2007) and PsEst1 esterase $(\sim 70 \mathrm{kDa})$ from Pseudomonas sp. strain B11-1 (Suzuki et al., 2003), were isolated and characterized. As discussed above, the PsEst1 enzyme shares a high sequence similarity with the EstS9 enzyme. This enzyme also consists of an N-terminal SGNH hydrolase-type domain and a C-terminal autotransporter beta domain (Fig. 1). The presence of the C-terminal AB-domain in EstS9 and PsEst1 suggests that both enzymes may be secreted by the type V secretion system (Henderson et al., 2004).

However, we could not identify any literature data which could confirm this hypothesis for PsEst1. Moreover, it is worthy to note that the presence of an $A B$-domain in the PsEst1 enzyme was not reported in the source article (Suzuki et al., 2003). For comparison, the EstA esterase from Psendoalteromonas sp. strain 643A is secreted by the type I secretion system (Dlugolecka et al., 2008), and characterized by its lack of a C-terminal AB-domain (Brzuszkiewicz et al., 2009).

Our literature search also revealed that the catalytically active N-terminal domain of enzymes secreted by the type $\mathrm{V}$ secretion mechanism (i) remains attached to the outer membrane, (ii) is autoproteolytically cleaved off, or (iii) is cleaved off by another protease (Henderson et al., 1998).

Hence, we hypothesized that the mature form of EstS9 may only be composed of a catalytic domain (EstS9 is secreted outside the bacterial cell) or be composed of a catalytic domain and an AB-domain (EstS) is anchored in the outer membrane and its catalytic domain is present outside the cell). For this reason, in this study, we decided to characterize and compare the biochemical properties of two recombinant forms of the EstS9 protein. The first one, called EstS9N, consists of an N-terminal catalytic domain and a C-terminal AB-domain. The second protein, called EstS9 $\Delta$, is characterized by the lack of a C-terminal AB-domain, and its amino acid sequence was designed based on the analysis of InterProScan results. Moreover, in both recombinant proteins, the putative signal peptide was removed. Also, a six-histidine tag (His-tag) was added to the C-terminus of both the EstS9N and EstS9 9 proteins to facilitate purification.

B

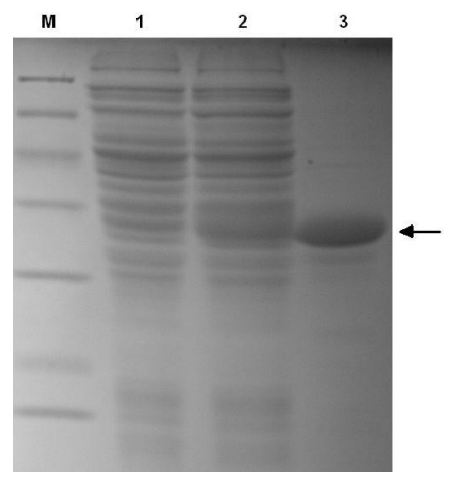

Figure 4B. SDS-PAGE protein profiles: (M) Unstained Protein Molecular Weight Marker 116, 66.2, 45, 35, 25, 18.4, 14.4 kDa (Thermo Scientific, USA), (1) Cell-free extract of $E$. coli TOP10/ pBADestS9 $\Delta,(2)$ Cell extract of $E$. coli TOP10/pBADestS9 $\Delta$ after solubilization of inclusion bodies, (3) Purified EstS9 $\Delta$ after renaturation 
Table 1. Relative activity of purified EstS9N enzyme with various nitrophenyl-derived chromogenic substrates

\begin{tabular}{lcl}
\hline Substrate & $\begin{array}{l}\text { No. of C atoms } \\
\text { in alkyl chain }\end{array}$ & $\begin{array}{l}\text { Relative activity } \\
{[\%]}\end{array}$ \\
\hline$p$-nitrophenyl acetate & 2 & $53 \pm 5.1$ \\
\hline$p$-nitrophenyl butyrate & 4 & $100 \pm 2.5$ \\
\hline$p$-nitrophenyl caprylate & 8 & $15.5 \pm 1.9$ \\
\hline$p$-nitrophenyl caproate & 10 & $6.9 \pm 0.8$ \\
\hline$p$-nitrophenyl palmitate & 16 & $<0.01$ \\
\hline$p$-nitrophenyl stearate & 18 & $<0.01$ \\
\hline
\end{tabular}

\section{Expression and purification of the EstS9N and EstS9D proteins}

The arabinose-inducible promoter of the pBAD/ Myc-His A plasmid was used for the expression of the estS9N and estS9A genes in E. coli TOP10 cells. The highest EstS9N and EstS9 $\Delta$ enzyme production yields were achieved by adding L-arabinose to a final concentration of $0.2 \% \mathrm{w} / \mathrm{v}$ at $\mathrm{OD}_{600}=0.5$ and by extending the cultivation at $30^{\circ} \mathrm{C}$ for $20 \mathrm{~h}$. The SDS-PAGE analysis of the E. coli cell lysates and cell debris revealed that both recombinant proteins were produced as inclusion bodies. As a result of this, both proteins were purified on a His-Trap affinity column under denaturating conditions and then renatured from urea. Interestingly, both PsEst1 esterase (Suzuki et al., 2003) and EstA esterase (Cieslinski et al., 2007; Dlugolecka et al., 2009) were also produced as inclusion bodies in $E$. coli and then purified under denaturating conditions. SDS-PAGE analysis of the eluted fraction showed distinct protein bands at $\sim 66 \mathrm{kDa}$ and $\sim 35 \mathrm{kDa}$, which are close to the predicted mass of the deduced EstS9N and EstS9 $\Delta$ proteins with the addition of a six-histidine tag, respectively (Fig. 4A and 4B). Preliminary experiments showed that $p$-nitrophenyl butyrate was hydrolyzed by both, the purified and renatured proteins. Moreover, the concentration of purified EstS9 $\Delta\left(1.25 \mathrm{mg} \mathrm{mL}^{-1}\right)$ was two times higher than the concentration of purified EstS9N $\left(0.58 \mathrm{mg} \mathrm{mL}^{-1}\right)$, however, the EstS9 $\Delta$ enzyme had only $\sim 3 \%$ of the specific enzymatic activity and $\sim 6 \%$ of the total enzymatic activity of

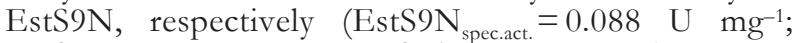
EstS9N $\mathrm{N}_{\text {total.act. }}=0.77 \mathrm{U}$; EstS9 $\Delta_{\text {spec.act. }}^{\text {spec.act. }}=0.0025 \mathrm{U} \mathrm{mg}^{-1}$; EstS9 $\left.\Delta_{\text {total act }}^{\text {total.act. }}=0.046 \mathrm{U}\right)$. Therefore, we decided to only characterize the EstS9N enzyme further.

\section{Substrate specificity, physicochemical characterization and determination of kinetic parameters of EstS9N}

Substrate specificity of EstS9N esterase was investigated using $p$-nitrophenyl esters of different alkyl chain lengths. As it is shown in Table 1, the EstS9N enzyme had a high activity towards short chain fatty acids (C2-C8), and exerted the maximum activity against the $p$-nitrophenyl butyrate ester. Importantly, the comparative analysis of results of $p$-nitrophenyl esters' hydrolysis by PsEst1 (Suzuki et al., 2003) and EstS9N enzymes revealed the distinct differences in substrate specificity for both compared enzymes. In contrast to PsEst1, the EstS9N enzyme showed a higher activity against $p$-nitrophenyl acetate and

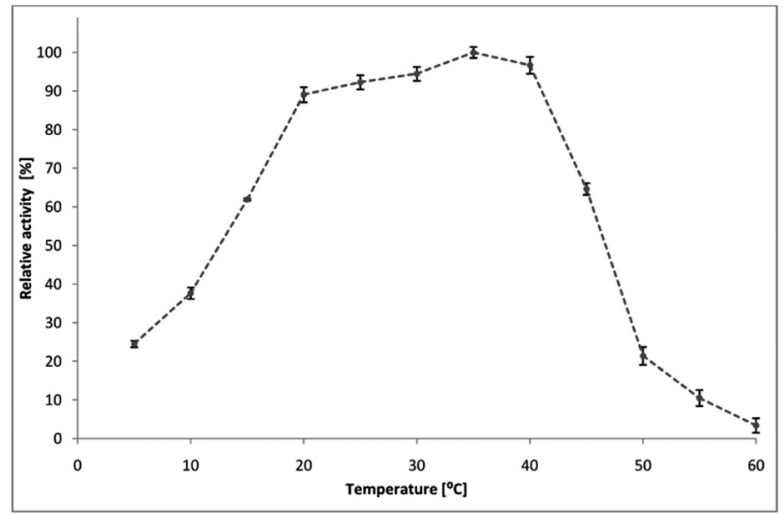

Figure 5. The effect of temperature on the recombinant EstS9N enzyme activity

The effect of temperature on the esterase activity was assayed by incubating the EstS9N enzyme ( $9 \mathrm{~min}$ ) at a temperature ranging from 5 to $60^{\circ} \mathrm{C}$ (at $5^{\circ} \mathrm{C}$ increments) with $p$-nitrophenyl butyrate at a final concentration of $3.6 \mathrm{mM}$, in $20 \mathrm{mM}$ Tris- $\mathrm{HCl}$ buffer, $\mathrm{pH}$ 7.5.

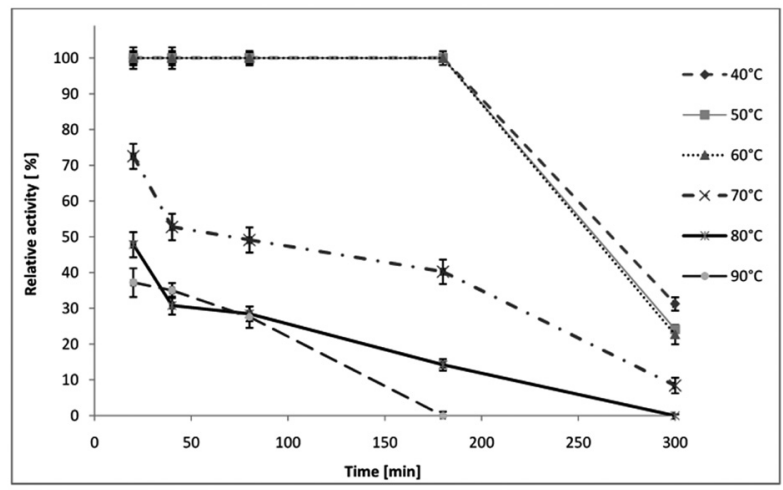

Figure 6. The effect of temperature on the recombinant EstS9N esterase stability

The purified enzyme was pre-incubated at 40, 50, 60, 70, 80 and $90^{\circ} \mathrm{C}$ in the absence of $p$-nitrophenyl butyrate, respectively. After incubation for different times (20,40,80, 180 and $300 \mathrm{~min})$, the residual activity of the enzyme was assayed under standard conditions (9 min incubation at $25^{\circ} \mathrm{C}, \mathrm{pH} 9.0$ ).

a lower activity against $p$-nitrophenyl caproate and caprylate, respectively.

The optimal temperature for the esterase activity of EstS9N was determined from 5 to $60^{\circ} \mathrm{C}$. As shown in Fig. 5, the maximum activity was at $35^{\circ} \mathrm{C}$, but the enzyme retained $\sim 90 \%$ of its activity in the range of $25-40^{\circ} \mathrm{C}$ and $\sim 40 \%$ of its activity at $10^{\circ} \mathrm{C}$. By comparison, the thermal optimum of PsEst 1 is $45^{\circ} \mathrm{C}$. Moreover, $100 \%$ of the EstS9N enzyme activity was retained after $3 \mathrm{~h}$ of incubation over a temperature range of 40 to $60^{\circ} \mathrm{C}$, and the enzyme was gradually inactivated by heat treatment at temperatures above $70^{\circ} \mathrm{C}$ (Fig. 6). The thermostability of the EstS9N enzyme was significantly higher than PsEst1 (Suzuki et al., 2003).

The optimal $\mathrm{pH}$ for the esterase activity of EstS9N was determined over a $\mathrm{pH}$ range of 2.0 to 12.0 , at $25^{\circ} \mathrm{C}$. As shown in Fig. 7 , the enzyme was active over a $\mathrm{pH}$ range of 5.5 to 10.5 and preferred alkaline conditions with an optimum activity at $\mathrm{pH}$ 9.0. The results from the $\mathrm{pH}$ stability assay showed that $\sim 100 \%$ of the enzyme activity was retained at the optimal $\mathrm{pH}$, however, at $\mathrm{pH} 8$ and $\mathrm{pH} \mathrm{10,} \mathrm{the} \mathrm{enzyme} \mathrm{was} \mathrm{gradu-}$ ally inactivated (Fig. 8). In contrast to the EstS9N esterase, the PsEst1 enzyme was stable under acidic and alkaline conditions (Suzuki et al., 2003). 


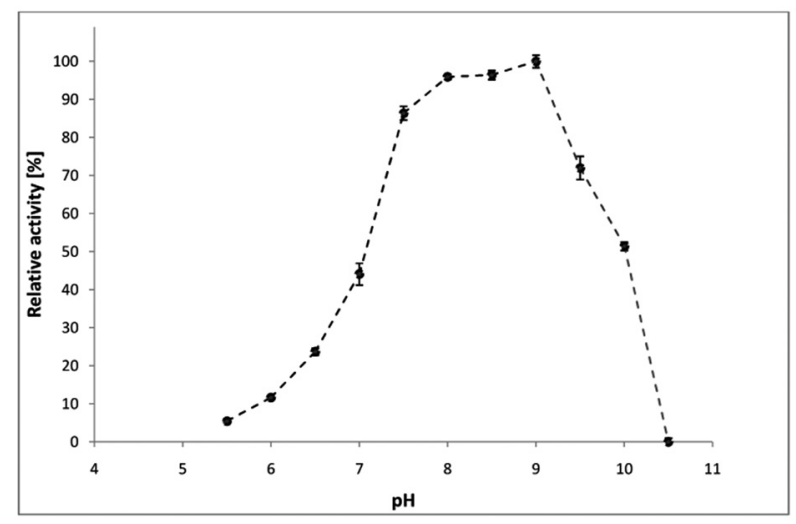

Figure 7. The effect of $\mathrm{pH}$ on the recombinant EstS9N enzyme activity

The enzymatic activity was assayed at the tested $\mathrm{pH}$ values (from $\mathrm{pH} 2.0$ to 12.0 ), at $25^{\circ} \mathrm{C}$, with $p$-nitrophenyl butyrate as a substrate.

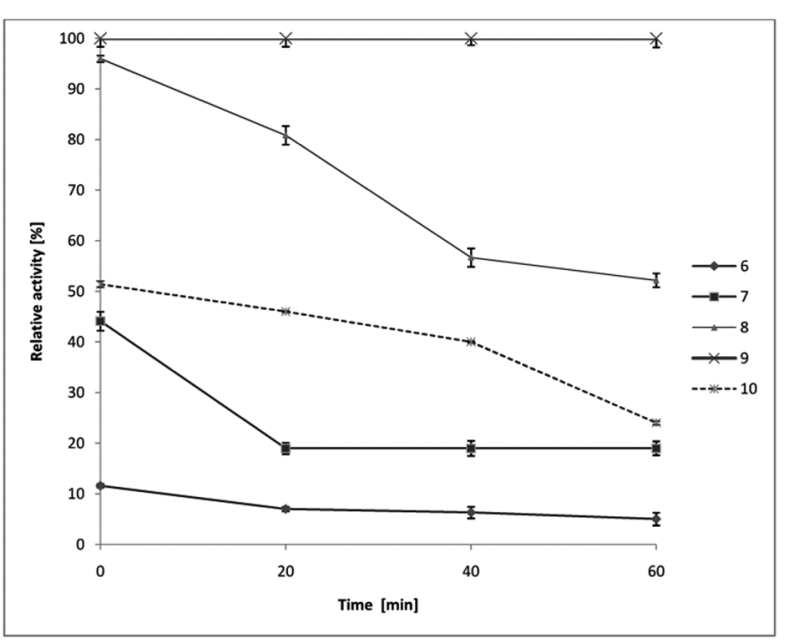

Figure 8. The effect of $\mathrm{pH}$ on the recombinant EstS9N esterase stability

$\mathrm{pH}$-stability was determined by incubation of the esterase for 0 , 20,40 and $60 \mathrm{~min}$ at various $\mathrm{pH}$, and then the residual activity of enzyme was assayed under standard conditions.

A study of its kinetic properties $\left(K_{m}, k_{c a t}\right.$ and $\left.k_{c a t}\right)$ $\left.K_{m}\right)$ revealed that EstS9N had lower affinities $\left(K_{m}\right.$ values) for $p$-nitrophenyl butyrate at the optimum temperature of enzymatic activity $\left(35^{\circ} \mathrm{C}\right)$ than at lower temperatures $\left(15^{\circ} \mathrm{C}\right.$ and $\left.25^{\circ} \mathrm{C}\right)$. Moreover, as shown in Table 2 , the $k_{\text {cat }} / K_{m}$ values for $p$-nitrophenyl butyrate at $25^{\circ} \mathrm{C}$ and $15^{\circ} \mathrm{C}$, are approximately 12 and 2 times higher than the $k_{\text {cat }} / K_{m}$ value at the optimum temperature of enzymatic activity. In summary, the EstS9N

Table 2. Kinetic parameters of EstS9N

The enzyme was incubated at 15,25 or $35^{\circ} \mathrm{C}$ with p-nitrophenyl butyrate at a final concentration of $3.6 \mathrm{mM}$, in $20 \mathrm{mM}$ Tris-HCl buff$\mathrm{er}, \mathrm{pH}$ 7.5. The enzymatic reaction was stopped after $9 \mathrm{~min}$ with isopropanol.

\begin{tabular}{llll}
\hline $\begin{array}{l}\text { Temperature } \\
{\left[{ }^{\circ} \mathrm{C}\right]}\end{array}$ & $\begin{array}{l}K_{\mathrm{m}} \\
{[\mathrm{mM}]}\end{array}$ & $\begin{array}{l}k_{\text {cat }} \\
{\left[\mathrm{s}^{-1}\right]}\end{array}$ & $\begin{array}{l}k_{\text {cat }} / K_{\mathrm{m}} \\
{\left[\mathrm{s}^{-1} \mathrm{mM}^{-1}\right]}\end{array}$ \\
\hline 15 & 0.0368 & 1.45 & 39.50 \\
\hdashline 25 & 0.0095 & 2.39 & 252.22 \\
\hline 35 & 0.1617 & 3.31 & 20.48 \\
\hline
\end{tabular}

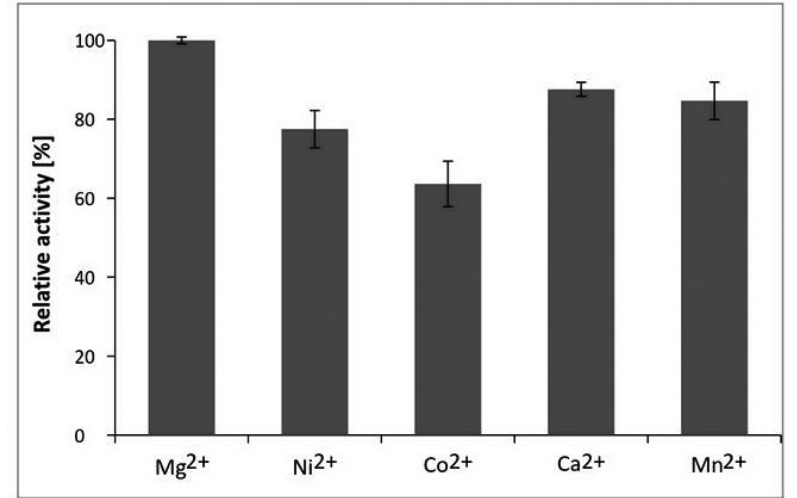

Figure 9. The effect of various metal ions on EstS9N esterase activity

The enzyme was incubated for $60 \mathrm{~min}$ at $25^{\circ} \mathrm{C}$ with $5 \mathrm{mM}$ metal ions, and then the residual activity of enzyme was assayed under standard conditions.

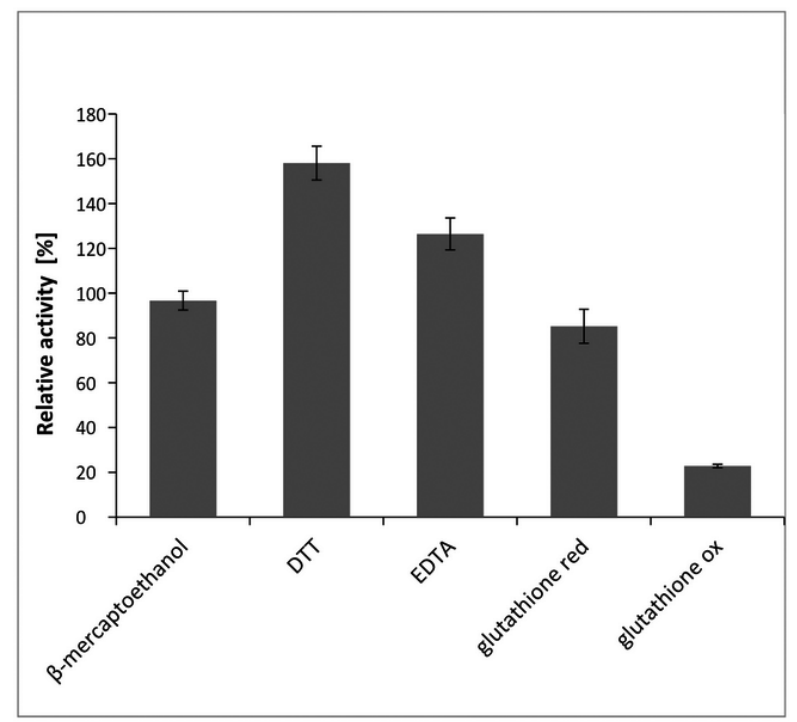

Figure 10. The effect of selected reagents on EstS9N esterase activity

The enzyme was incubated for $60 \mathrm{~min}$ at $25^{\circ} \mathrm{C}$ with $5 \mathrm{mM}$ of $\beta$-mercaptoethanol, DTT, EDTA, glutathione in reduced and oxidized states, and then the residual activity of enzyme was assayed under standard conditions.

enzyme has the highest enzymatic efficiency known at a temperature close to the growth optimum for Pseudomonas sp. S9 $\left(20^{\circ} \mathrm{C}\right)$.

As shown in Fig. 9, the hydrolytic activity of EstS9N against $p$-nitrophenyl butyrate as a substrate, was clearly inhibited by $\mathrm{Ni}^{2+}, \mathrm{Co}^{2+}, \mathrm{Ca}^{2+}$, and $\mathrm{Mn}^{2+}$ ions. We also observed that the addition of EDTA to freshly purified enzyme markedly increased its enzymatic activity (Fig. 10). Hence, it seems to be highly possible that EDTA chelated the $\mathrm{Ni}^{2+}$ ions which were co-eluted with the enzyme during its purification on the Ni-NTA column helping to restore the enzyme activity.

The Cys residues are not directly involved in the catalysis of the hydrolysis reaction catalyzed by lipolytic enzymes belonging to the GDSL subfamily. However, the presence of two putative disulfide bonds (predicted with the DiANNA 1.1 program), which could be present in native enzyme or could be formed during 
refolding process, encouraged us to check the effect of selected reducing or oxidizing agents on enzymatic activity of EstS9 esterase. As shown in Fig. 10, dithiothreitol (reducing agent) significantly increased the enzyme activity, whereas oxidized glutathione (oxidizing agent) significantly decreased its activity. Hence, we hypothesized that the positive effect of the DTT on the EstS9N enzymatic activity may be a result of the reduction of an intramolecular and/or intermolecular disulfide bond (or bonds) between the cysteine residues of the analyzed enzyme, which could be formed during enzyme production and/or purification. $\beta$-Mercaptoethanol and glutathione (reduced form), two other reducing agents, did not have an effect on the enzyme activity. However, it may be possible that these compounds could not reduce the putative disulfide bonds formed in EstS9N because these are weaker reducing agents than dithiothreitol.

\section{CONCLUSION}

Although there is a significant knowledge about cold active esterases belonging to GXSXG subfamily, the data available on the cold active esterases belonging to GDSL subfamily is very poor. In this study, we identified, isolated and partially characterized two recombinant variants of EstS9, a putative cold active esterase belonging to GDSL subfamily. The results of the study confirmed that both recombinant variants of EstS9 protein have esterase activity. Moreover, the study on EstS9N kinetic properties showed that this recombinant variant of EstS9 enzyme is a cold active esterase.

On the other hand, despite the fact that the yield of the purified EstS9 $\Delta$ enzyme was remarkably higher than that for the purified EstS9N, its enzymatic activity was also much lower than EstS9N. Hence, taking into account that the EstS9 enzyme could be secreted by the type $\mathrm{V}$ secretion mechanism, we hypothesized that the obtained results may suggest that the mature form of the native EstS9 enzyme is composed of two domains. Evidence for this hypothesis was supported by the results of Wilhelm and coworkers who reported that the mature form of EstA esterase, isolated from mesophilic Pseudomonas aureginosa strain PAO1, is located in the outer membrane of the host cell and is composed of an N-terminal catalytic domain and a C-terminal autotransporter domain (Wilhelm et al., 1999). Therefore, our future work will include production and characterization of the native EstS9 enzyme. Additionally, we plan to build on the esterolytic activity of the EstS9 $\Delta$ enzyme by employing an in vitro directed molecular evolution for the generation of EstS9 $\Delta$-derivatives for selection of a stable and efficient biocatalyst. If this approach proves successful, the selected EstS9 $\Delta$-derivative will be enzymatically characterized and its biotechnological potential will be evaluated.

\section{REFERENCES}

Abdul Salam J, Lakshmi V, Das D, Das N (2013) Biodegradation of lindane using a novel yeast strain, Rhodotorula sp. VITJzN03 isolated from agricultural soil. World J Microb Biotechol 29: 475-87. doi: 10.1007/s11274-012-1201-4.

Akoh CC, Lee GC, Liaw YC, Huang TH, Shaw JF (2004) GDSL family of serine esterases/lipases. Prog Lipid Res 43: 534-552. doi: 10.1016/j.plipres.2004.09.002.
Arpigny JL, Jaeger KE (1999) Bacterial lipolytic enzymes: classification and properties. Biochem J 343: 177-83. doi: 10.1042/02646021:3430177.

Berlemont R, Jacquin O, Delsaute M, La Salla M, Georis J, Verte F, Galleni M, Power P (2013) Novel cold-adapted esterase mhlip from an antarctic soil metagenome. Biology 2: 177-188. doi:10.3390/biology2010177.

Brault G, Shareck F, Hurtubise Y, Lepine F, Doucet N (2012) Isolation and characterization of EstC, a new cold-active esterase from Streptomyces coelicolor A3(2). PloS one 7: e32041. doi: 10.1371/journal. pone.0032041.

Brzuszkiewicz A, Nowak E, Dauter Z, Dauter M, Cieslinski H, Dlugolecka A, Kur J (2009) Structure of EstA esterase from psychrotrophic Pseudoalteromonas sp 643A covalently inhibited by monoethylphosphonate. Acta Crystallogr F 65: 862-865. doi: 10.1107/ S1744309109030826.

Cavicchioli R, Charlton T, Ertan H, Mohd Omar S, Siddiqui KS, Williams TJ (2011) Biotechnological uses of enzymes from psychrophiles. Microb Biotechnol 4: 449-460. doi: 10.1111/j.17517915.2011.00258.x.

Cieslinski H, Bialkowska AM, Dlugolecka A, Daroch M, Tkaczuk KL, Kalinowska H, Kur J, Turkiewicz M (2007) A cold-adapted esterase from psychrotrophic Pseudoalteromas sp strain 643A. Arch Microbiol 188: 27-36. doi: 10.1007/s00203-007-0220-2.

Dlugolecka A, Cieslinski H, Bruzdziak P, Gottfried K, Turkiewicz M, Kur J (2009) Purification and biochemical characteristic of a coldactive recombinant esterase from Pseudoalteromonas sp 643A under denaturing conditions. Pol J Microbiol 58: 211-218.

Dlugolecka A, Cieslinski H, Turkiewicz M, Bialkowska AM, Kur J (2008) Extracellular secretion of Pseudoalteromonas sp cold-adapted esterase in Escherichia coli in the presence of Pseudoalteromonas $\mathrm{sp}$ components of ABC transport system. Protein Expres Purif 62: 179184. doi: 10.1016/j.pep.2008.07.006.

Esteban-Torres M, Mancheno JM, de las Rivas B, Munoz R (2014) Characterization of a cold-active esterase from Lactobacillus plantarum suitable for food fermentations. I Agr Food Chem 62: 5126-5132. doi: $10.1021 /$ jf501493z.

Fojan P, Jonson PH, Petersen MT, Petersen SB (2000) What distinguishes an esterase from a lipase: a novel structural approach. Biochimie 82: 1033-1041. doi: 10.1016/S0300-9084(00)01188-3.

Fu J, Leiros HKS, de Pascale D, Johnson KA, Blencke HM, Landfald B (2013) Functional and structural studies of a novel cold-adapted esterase from an Arctic intertidal metagenomic library. Appl Microbiol Biot 97: 3965-3978. doi: 10.1007/s00253-012-4276-9.

Fu C, Hu Y, Xie F, Guo H, Ashforth EJ, Polyak SW, Zhu B, Zhang L (2011) Molecular cloning and characterization of a new cold-active esterase from a deep-sea metagenomic library. Appl Microbiol Biotechnol 90: 961-970. doi: 10.1007/s00253-010-3079-0.

Heath C, Hu XP, Cary SC, Cowan D (2009) Identification of a novel alkaliphilic esterase active at low temperatures by screening a metagenomic library from antarctic desert soil. Appl Environ Microb 75: 4657-4659. doi: 10.1128/AEM.02597-08.

Henderson IR, Navarro-Garcia F, Desvaux M, Fernandez RC, Ala'Aldeen D (2004) Type V protein secretion pathway: the autotransporter story. Microbiol Mol Biol R 68: 692-744. doi:10.1016/ s0966-842x (98)01318-3.

Henderson IR, Navarro-Garcia F, Nataro JP (1998) The great escape: structure and function of the autotransporter proteins. Trends Microbiol 6: 370-378. doi:10.1016/s0966-842x(98)01318-3

Hu XP, Heath C, Taylor MP, Tuffin M, Cowan D (2012) A novel, extremely alkaliphilic and cold-active esterase from Antarctic desert soil. Extremophiles 16: 79-86. doi: 10.1007/s00792-011-0407-y.

Jang SH, Kim J, Kim J, Hong S, Lee C (2012) Genome sequence of cold-adapted Psendomonas mandelii strain JR-1. J Bacteriol 194: 32633263. doi: 10.1128/JB.00517-12.

Jiang X, Xu X, Huo Y, Wu Y, Zhu X, Zhang X, Wu M (2012) Identification and characterization of novel esterases from a deep-sea sediment metagenome Arch Microbiol 194: 207-214. doi: 10.1007/ s00203-011-0745-2.

Jimenez DJ, Montana JS, Alvarez D, Baena S (2012) A novel cold active esterase derived from Colombian high Andean forest soil metagenome. World J Microb Biot 28: 361-70. doi: 10.1007/s11274011-0828-x.

Kang CH, Oh KH, Lee MH, Oh TK, Kim BH, Yoon J (2011) A novel family VII esterase with industrial potential from compost metagenomic library. Microb Cell Fact 10: 41. doi: 10.1186/1475-2859-10-41.

Kim YO, Park IS, Nam BH, Kim DG, Jee YJ, Lee SJ, An CM (2014) A novel esterase from Paenibacillus sp. PBS-2 is a new member of the beta-lactamase belonging to the family VIII lipases/esterases. I Microbiol Biotechn 24: 1260-1268.

Kulakova L, Galkin A, Nakayama T, Nishino T, Esaki N (2004) Coldactive esterase from Psychrobacter sp. Ant300: gene cloning, characterization, and the effects of Gly-->Pro substitution near the active site on its catalytic activity and stability. Biochim Biophys Acta, 1696: 59-65. doi: 10.1016/j.bbapap.2003.09.008. 
Laemmli UK (1970) Cleavage of Structural Proteins during Assembly of Head of Bacteriophage-T4. Nature 227: 680-685. doi: 10.1038/227680a0.

Lemak S, Tchigvintsev A, Petit P, Flick R, Singer AU, Brown G, Evdokimova E, Egorova O, Gonzalez CF, Chernikova TN, Yakimov MM, Kube M, Reinhardt R, Golyshin PN, Savchenko A, Yakunin AF (2012) Structure and activity of the cold-active and anion-activated carboxyl esterase OLEI01171 from the oil-degrading marine bacterium Oleispira antarctica. Biochem J 445: 193-203. doi: 10.1042/ BJ20112113.

Novototskaya-Vlasova K, Petrovskaya L, Yakimov S, Gilichinsky D (2012) Cloning, purification, and characterization of a cold-adapted esterase produced by Psychrobacter cryobalolentis K5T from Siberian cryopeg. Fems Microbiol Ecol 82: 367-375. doi: 10.1111/j.15746941.2012.01385.x.

Reddy PVV, Rao SSSN, Pratibha MS, Sailaja B, Kavya B, Manorama RR, Singh SM, Srinivas TNR, Shivaji S (2009) Bacterial diversity and bioprospecting for cold-active enzymes from culturable bacteria associated with sediment from a melt water stream of Midtre Lovenbreen glacier, an Arctic glacier. Res Microbiol 160: 538-546. doi: 10.1016/j.resmic.2009.08.008.

Soror SH, Verma V, Rao R, Rasool S, Koul S, Qazi GN, Cullum J (2007) A cold-active esterase of Streptomyces coelicolor A3(2): from ge- nome sequence to enzyme activity. I Ind Microbiol Biot 34: 525-531. doi: 10.1007/s10295-007-0224-6.

Suzuki T, Nakayama T, Choo DW, Hirano Y, Kurihara T, Nishino T, Esaki N (2003) Cloning, heterologous expression, renaturation, and characterization of a cold-adapted esterase with unique primary structure from a psychrotroph Pseudomonas sp. strain B11-1. Protein Expres Purif 30: 171-178. doi: 10.1016/S1046-5928(03)00128-1.

Suzuki T, Nakayama T, Kurihara T, Nishino T, Esaki N (2002) Primary structure and catalytic properties of a cold-active esterase from a psychrotroph, Acinetobacter sp. strain No. 6. isolated from Siberian soil. Biosci Biotech Bioch 66: 1682-1690. doi: 10.1271/bbb.66.1682.

Weisburg WG, Barns SM, Pelletier DA, Lane DJ (1991) 16S ribosomal DNA amplification for phylogenetic study. J Bacteriol 173: 697-703.

Wierzbicka-Wos A, Bartasun P, Cieslinski H, Kur J (2013) Cloning and characterization of a novel cold-active glycoside hydrolase family 1 enzyme with beta-glucosidase, beta-fucosidase and beta-galactosidase activities. BMC Biotechnol 13: 22. doi: 10.1186/1472-6750-13-22.

Wilhelm S, Tommassen J, Jaeger KE (1999) A novel lipolytic enzyme located in the outer membrane of Pseudomonas aeruginosa. I Bacteriol 181: 6977-6986. 